\title{
Use of $\beta$-Blockers and the Risk of Hip/Femur Fracture in the United Kingdom and The Netherlands
}

\author{
F. de Vries, ${ }^{1}$ P. C. Souverein, ${ }^{1}$ C. Cooper,${ }^{2}$ H. G. M. Leufkens, ${ }^{1}$ T. P. van Staa ${ }^{1,3}$ \\ ${ }^{1}$ Division of Pharmacoepidemiology and Pharmacotherapy, Utrecht Institute for Pharmaceutical Sciences, Faculty of Science, Universiteit Utrecht, \\ Sorbonnelaan 16, 3584 CA Utrecht, The Netherlands \\ ${ }^{2}$ MRC Epidemiology Resource Centre, University of Southampton, MP95, Southampton General Hospital, Southampton, SO16 6YD, \\ United Kingdom \\ ${ }^{3}$ General Practice Research Database Division, The Medicines and Healthcare Products Regulatory Agency, 15th floor, Market Towers, \\ 1 Nine Elms Lane, London, SW8 5NQ, United Kingdom
}

Received: 5 August 2006 / Accepted: 11 October 2006 / Online publication: 2 February 2007

\begin{abstract}
Data from in vivo studies have indicated a role for $\beta$-blockers in the prevention of bone loss. Some epidemiological studies have found protective effects of $\beta$-blockers on fracture risk. However, there is limited information on the association with cumulative dose and type of $\beta$-blockers used. We conducted two casecontrol studies using data from the UK General Practice Research Database (GPRD) and the Dutch PHARMO Record Linkage System (RLS). Cases were patients with a first hip or femur fracture; controls were individually matched on practice/region, gender, year of birth, and calendar time. Current use of $\beta$-blockers was defined as a prescription in 90 days before the index date. We adjusted for medical conditions and drugs associated with falling or bone mineral density. Odds ratios (ORs) and 95\% confidence intervals (CIs) were calculated using conditional logistic regression analysis. The study population included 22,247 cases and controls in the GPRD and 6,763 cases and 26,341 controls in the PHARMO RLS. Current use of $\beta$-blockers was associated with a reduced risk of hip/femur fracture in both the GPRD (adjusted OR $=0.82,95 \%$ CI $0.74-0.91$ ) and PHARMO RLS (adjusted OR $=0.87$, 95\% CI $0.80-0.95$ ) study populations. However, this reduction of risk was not associated with cumulative dose, lipophilicity, or receptor selectivity of $\beta$-blockers. The protective effect of $\beta$-blockers was only present among patients with a history of use of other antihypertensive agents (GPRD adjusted OR $=0.72,95 \%$ CI $0.64-0.83$; PHARMO RLS adjusted OR $=0.76,95 \%$ CI $0.67-0.86$ ) but not in patients using $\beta$-blockers only (GPRD adjusted $\mathrm{OR}=0.97$, 95\% CI 0.82-1.14; PHARMO RLS adjusted $\mathrm{OR}=1.01,95 \% \mathrm{CI} 0.90-1.14)$. Also, in patients with a history of use of other antihypertensive agents, no dose-response relationship with $\beta$-blocker use was found. The effect was constant with cumulative dose and the OR was below 1.0 even among patients who just started treatment with $\beta$-blockers. As the mechanism by which $\beta$-blockers could influence bone mineral density is
\end{abstract}

Correspondence to: P. C. Souverein; E-mail: p.c.souverein@, pharm.uu.nl likely to need some time to exert a clinically relevant effect, all these finding suggests that the association between $\beta$-blockers and fracture risk is not causal.

Key words: $\beta$-Blocker - Fracture - Osteoporosis Epidemiology — Case-control

Bone remodeling comprises a phase of resorption by osteoclasts and a phase of formation by osteoblasts. Recent studies have shown bone metabolism to be mediated through the autonomic central nervous system. Leptin, a hormone produced in fat cells to signal energy insufficiency, regulates bone remodeling by modulating osteoblast proliferation and subsequent osteoclast activation via the osteoclast differentiation factor receptor activator of nuclear factor $\mathrm{\kappa B}$ ligand (RANKL). The antiosteogenic effect of leptin is not present in $\beta_{2}$-adrenergic receptor-deficient mice, which had actual increases in bone mineral density (BMD) [1-5]. Data from these in vivo studies indicate a role for $\beta$-blockers in the prevention of bone loss. In the early 1990s, propranolol was found to increase bone formation [6]. Some observational studies have reported that use of $\beta$-blockers was associated with a decreased risk of fractures [7-9], conflicting with other studies which found no association with fractures [10-12]. Studies on the effects of $\beta$-blockers on subclinical endpoints, like BMD or biochemical markers of bone resorption, have also yielded inconsistent results $[7,10,12-14]$.

A possible role for $\beta$-blockers in the prevention of fractures is of major clinical interest, given that fractures are a major source of morbidity, disability, hospitalization, and mortality. One of the most serious fractures 
resulting from accidental falls is hip fracture [15]. However, there is still a lack of knowledge with respect to the effects of cumulative dose and type of $\beta$-blockers used. Thus, the objective of this study was to assess the strength of the association between use of $\beta$-blockers and risk of hip/femur fractures using data from two different large population-based databases in the United Kingdom and The Netherlands.

\section{Materials and Methods}

\section{Setting}

Data for this study were obtained from the UK General Practice Research Database (GPRD) and the Dutch PHARMO Record Linkage System (RLS). The GPRD contains the computerized medical records of general practices across the United Kingdom (www.gprd.com). Approximately $6 \%$ of the total registered population of England and Wales is represented in the database, and it includes a cumulative total of over 5 million adult patients. The age and sex distribution of patients enrolled is representative of the general English and Welsh populations. Patient details accrued in the GPRD include demographic information, diagnoses, prescription details, preventive care provided, referrals to specialist care, hospital admissions, and related major outcomes [16]. Clinical data are stored and retrieved by means of Oxford Medical Information Systems and Read codes for diseases or causes of morbidity and mortality that are cross-referenced to the International Classification of Diseases (ICD-9). Several independent validation studies have shown that the GPRD has a high level of completeness and validity, including for hip fractures $[17,18]$

The PHARMO RLS includes the demographic details and complete medication history of 950,000 community-dwelling residents of more than 25 population-defined areas in The Netherlands from 1985 onward. It is further linked to hospital admission records as well as several other health registries, including pathology, clinical laboratory findings, and general practitioner data (www.pharmo.nl). Since the majority of all patients in The Netherlands are registered only with one community pharmacy, independently of prescriber, pharmacy records are virtually complete with regard to prescription drugs. For this study, drug-dispensing and hospitalization data were used. The computerized histories record information on the type of drug dispensed, dispensing date, prescriber, amount dispensed, and prescribed dosage regimen. Hospital discharge records include detailed information on the primary and secondary discharge diagnoses; diagnostic, surgical, and treatment procedures; type and frequency of consultations with medical specialists; and dates of hospital admission and discharge. All diagnoses are coded according to the ICD-9-CM [19].

\section{Definition of Cases and Controls}

GPRD. A case-control study was conducted using GPRD data collected from January 1987 to July 1999. The details of this study have been described elsewhere [20, 21]. Briefly, cases were defined as patients aged 18 years and older with a first record of a hospital admission for a hip/femur fracture (ICD-9 codes 820-821) recorded in their medical records between the enrollment date of their practice in the GPRD and the end of data collection. The date of the occurrence of the hip/femur fracture was the index date. Each case was matched by year of birth, sex, medical practice, and calendar time to one control patient without a history of a fracture. If no eligible control was available, the age criterion was expanded consecutively at 1 -yearly intervals to a maximum of
10 years. If no eligible control patient could be found, then an age- and sex-matched control patient from another practice was selected.

PHARMO RLS. Cases were patients aged 18 years and older with a first admission for a hip/femur fracture between January 1, 1991, and December 31, 2002. The date of the hospital admission was the index date. Up to four control patients, who did not have a history of any type of fracture, were matched to each case by year of birth, gender, region, and calendar time.

\section{Exposure Assessment}

For each patient, we identified all prescriptions for (GPRD) and dispensing of (PHARMO RLS) $\beta$-blockers prior to the index date. Current users were defined as patients who had a prescription/dispensing for $\beta$-blockers within 3 months prior to the index date. Recent users received a last prescription/dispensing 3-6 months before the index date, past users 6-12 months before the index date, and distant past users more than 12 months before the index date. The last prescribed daily dose prior to the index date was obtained from the written dosage instructions. For each patient, cumulative exposure to $\beta$-blockers ever before the index date was calculated. The effect of cumulative dose was assessed both regardless of the timing of use and stratified to current, recent, past, and distant past use. Thus, current users could be classified to a low previous cumulative exposure (e.g., one or two 30-day prescriptions) or a high previous cumulative exposure (e.g., 100 30-day prescriptions). The estimated daily dose for each class of $\beta$-blocker was expressed as a fraction of the World Health Organization defined daily dose (DDD). A DDD is defined as the assumed average maintenance dose per day for a drug if used for its main indication in adults [22]. DDD equivalents can be used to compare drugs within a certain therapeutic group. In this study, we converted the DDD equivalents to milligrams of metoprolol, similar to the approach used in previous studies [21]. Furthermore, $\beta$-blockers were categorized according to receptor selectivity and lipophilicity based on data in handbooks on clinical pharmacology and therapeutics.

\section{Statistical Analysis}

The strength of the association between use of $\beta$-blockers and risk of hip/femur fractures was estimated using conditional logistic regression analysis (SAS version 9.1.3, PHREG procedure; SAS Institute, Cary, NC) and expressed as odds ratios (ORs) and 95\% confidence intervals (CIs). Final regression models were determined by stepwise backward elimination using a significance level of 0.05 . Smoothing spline regression plots were used to visualize the effect of cumulative $\beta$-blocker dose on risk of hip/femur fractures [23].

In our analysis, we controlled for a wide range of clinical variables that have been associated with risk of falls or fractures. In the GPRD study, we included the following variables in the final model: history of diabetes mellitus, rheumatoid arthritis, hyperthyroidism, congestive heart failure, seizures, anemia, dementia, depression, psychotic disorder, cerebrovascular accident, chronic obstructive pulmonary disease, osteoporosis, and a record of back pain or falls in the year before the index date. Furthermore, prescriptions, in the 6 months prior to the index date, for anticonvulsants, nonsteroidal anti-inflammatory drugs (NSAIDs), methotrexate, hormone replacement therapy, other hypertensive drugs (lowceiling diuretics, renin-angiotensin-aldosterone system [RAAS] inhibitors, calcium channel blockers), anxiolytics/ hypnotics, antipsychotics, antidepressants, anti-Parkinson drugs, oral and inhaled glucocorticoids, and bronchodilators as well as information on body mass index (BMI) were retained in the model. In the PHARMO RLS study, variables 
Table 1. Characteristics of hip/femur fracture cases and controls in the GPRD and PHARMO RLS

\begin{tabular}{|c|c|c|c|c|}
\hline \multirow[b]{2}{*}{ Characteristic } & \multicolumn{2}{|l|}{ GPRD } & \multicolumn{2}{|l|}{ PHARMO RLS } \\
\hline & $\begin{array}{l}\text { Cases } \\
(n=22,247)\end{array}$ & $\begin{array}{l}\text { Controls } \\
(n=22,247)\end{array}$ & $\begin{array}{l}\text { Cases } \\
(n=6,763)\end{array}$ & $\begin{array}{l}\text { Controls } \\
(n=26,341)\end{array}$ \\
\hline \multicolumn{5}{|l|}{ Gender } \\
\hline Women & $75.8 \%$ & $75.8 \%$ & $72.9 \%$ & $72.7 \%$ \\
\hline \multicolumn{5}{|l|}{ Age (years) } \\
\hline$<65$ & $13.9 \%$ & $13.9 \%$ & $15.8 \%$ & $16.2 \%$ \\
\hline $65-79$ & $30.8 \%$ & $32.2 \%$ & $36.6 \%$ & $37.3 \%$ \\
\hline$\geq 80$ & $55.2 \%$ & $53.9 \%$ & $47.6 \%$ & $46.5 \%$ \\
\hline Smoking ${ }^{\mathrm{a}}$ & $22.1 \%$ & $20.6 \%$ & No data available & \\
\hline \multicolumn{5}{|l|}{$\mathrm{BMI}^{\mathrm{b}}$} \\
\hline $20-25$ & $46.6 \%$ & $42.4 \%$ & & \\
\hline$<20$ & $18.0 \%$ & $9.7 \%$ & No data available & \\
\hline$>25$ & $35.4 \%$ & $47.9 \%$ & & \\
\hline Antidepressants & $13.0 \%$ & $7.2 \%$ & $9.5 \%$ & $5.1 \%$ \\
\hline Oral glucocorticoids & $7.2 \%$ & $4.4 \%$ & $5.4 \%$ & $3.5 \%$ \\
\hline Thiazides & $11.9 \%$ & $12.9 \%$ & $12.1 \%$ & $11.4 \%$ \\
\hline Nitrates & $6.9 \%$ & $7.4 \%$ & $9.4 \%$ & $9.1 \%$ \\
\hline Hormone replacement & $0.6 \%$ & $1.2 \%$ & $1.1 \%$ & $1.3 \%$ \\
\hline
\end{tabular}

a No data on smoking status for $45 \%$ of GPRD study population

${ }^{\mathrm{b}}$ No data on BMI for $58.5 \%$ of GPRD study population

included in the final model were a dispensing of benzodiazepines in the 3 months prior to the index date, or, in the 6 months prior to the index date, a dispensing of oral glucocorticoids, inhaled glucocorticoids, bronchodilators, statins, BMD-modifying drugs, hormone replacement therapy, antipsychotics, antidepressants, opioids, antiepileptics, other hypertensive drugs (low-ceiling diuretics, RAAS inhibitors, calcium channel blockers), antidiabetics, laxants, disease-modifying antirheumatic drugs, NSAIDs, or metoclopramide. A history of hospital admission for cerebrovascular disease, cancer, endocrine disorders, inflammatory bowel disease and other bowel diseases, obstructive airway disease, musculoskeletal and connective tissue diseases, anemia, and skin diseases prior to the index date were also included in the final model.

\section{Results}

The study population in the GPRD comprised 22,247 cases and 22,247 controls, whereas in the PHARMO RLS 6,763 cases and 26,341 controls were identified. The characteristics of both populations are displayed in Table 1. The sex and age distributions of cases were similar in the two case-control sets, although more cases in the GPRD set were aged over 80 years.

Current use of $\beta$-blockers was associated with a significantly decreased risk of hip/femur fracture in both databases, whereas recent and past use was not (Table 2). Adjusted ORs for current $\beta$-blocker users were 0.83 (95\% CI $0.75-0.92)$ in the GPRD and 0.87 (95\% CI 0.80-0.95) in the PHARMO RLS. There was no strong effect of cumulative dose among current users of $\beta$-blockers in either data set (Fig. 1), while assessing the effect cumulative dose irrespective of timing of use yielded similar results.
The most frequently prescribed $\beta$-blocker in the GPRD was atenolol (3.0\% among cases vs. $4.0 \%$ among controls, adjusted $\mathrm{OR}=0.80,95 \% \quad \mathrm{CI}$ 0.71-0.90). Current use of other $\beta$-blockers was infrequent (propranolol $0.4 \%$ vs. $0.5 \%$, metoprolol $0.2 \%$ vs. $0.2 \%$ ) and not associated with a decreased risk of hip/femur fracture (adjusted OR $=0.90,95 \% \mathrm{CI}$ 0.76-1.06). In the PHARMO RLS, the most frequently used $\beta$-blockers at the index date were metoprolol (4.6\% among cases vs. 5.6\% among controls), atenolol (3.2\% vs. 3.6\%), sotalol (1.9\% vs. $1.5 \%)$, and propranolol $(0.9 \%$ vs. $0.9 \%)$. The adjusted ORs for current use of metoprolol and atenolol were $0.79(95 \%$ CI 0.69-0.90) and 0.89 (95\% CI 0.77-1.04), respectively. Current use of propranolol (adjusted $\mathrm{OR}=0.98,95 \mathrm{CI}$ 0.74-1.21) and sotalol (adjusted $\mathrm{OR}=1.15,95 \% \mathrm{CI} 0.93-1.42$ ) were not associated with a protective effect of hip/femur fracture.

Categorizing $\beta$-blockers according to their lipophilicity, receptor selectivity, or last prescribed daily dose did not reveal major differences in effect (Table 2), nor did stratification according to age and gender (Table 3 ).

The protective effect of $\beta$-blockers was only present among patients who had been treated with other antihypertensive agents (e.g., low-ceiling diuretics, calcium antagonists, RAAS inhibitors), either concurrently or in the past (Table 3 ). This finding was consistent in both the GPRD (adjusted OR $=0.73,95 \%$ CI 0.64-0.83) and PHARMO RLS (adjusted $\mathrm{OR}=0.76,95 \%$ CI 0.67-0.86). Among patients using only $\beta$-blockers, the adjusted ORs were close to unity. In both data sets, the interaction term between 
Table 2. Use of $\beta$-blockers and risk of hip/femur fracture in the GPRD and PHARMO RLS

\begin{tabular}{|c|c|c|c|c|c|c|c|c|}
\hline \multirow[b]{2}{*}{$\beta$-blocker exposure } & \multicolumn{4}{|c|}{ GPRD } & \multicolumn{4}{|c|}{ PHARMO RLS } \\
\hline & $\begin{array}{l}\text { Cases } \\
(\%)\end{array}$ & $\begin{array}{l}\text { Controls } \\
(\%)\end{array}$ & $\begin{array}{l}\text { Crude OR } \\
(95 \% \mathrm{CI})\end{array}$ & $\begin{array}{l}\text { Adjusted OR } \\
(95 \% \mathrm{CI})^{\mathrm{a}}\end{array}$ & $\begin{array}{l}\text { Cases } \\
(\%)\end{array}$ & $\begin{array}{l}\text { Controls } \\
(\%)\end{array}$ & $\begin{array}{l}\text { Crude OR } \\
(95 \% \mathrm{CI})\end{array}$ & $\begin{array}{l}\text { Adjusted OR } \\
(95 \% \mathrm{CI})^{\mathrm{a}}\end{array}$ \\
\hline \multicolumn{9}{|l|}{ Timing of use } \\
\hline Current use & 4.5 & 5.9 & $0.70(0.64-0.77)$ & $0.82(0.74-0.91)$ & 12.4 & 13.7 & $0.91(0.83-0.98)$ & $0.87(0.80-0.95)$ \\
\hline Recent use & 0.6 & 0.6 & $0.89(0.70-1.14)$ & $0.88(0.68-1.15)$ & 1.7 & 1.7 & $1.01(0.82-1.24)$ & $0.93(0.75-1.15)$ \\
\hline Past use & 0.7 & 0.6 & $1.10(0.86-1.40)$ & $0.99(0.76-1.28)$ & 1.4 & 1.3 & $1.11(0.88-1.40)$ & $0.99(0.78-1.26)$ \\
\hline Distant past use & 3.7 & 2.8 & $1.10(0.98-1.22)$ & $1.06(0.94-1.20)$ & 6.8 & 6.3 & $1.07(0.96-1.20)$ & $0.97(0.87-1.09)$ \\
\hline \multicolumn{9}{|c|}{ Among current users of $\beta$-blockers } \\
\hline \multicolumn{9}{|l|}{ Selectivity } \\
\hline Low & 1.0 & 1.2 & $0.75(0.63-0.90)$ & $0.86(0.71-1.05)$ & 3.5 & 3.1 & $1.12(0.97-1.30)$ & $1.04(0.89-1.21)$ \\
\hline Medium & 0.1 & 0.2 & $0.79(0.48-1.32)$ & $0.81(0.47-1.41)$ & 0.3 & 0.5 & $0.40(0.20-0.84)$ & $0.38(0.18-0.79)$ \\
\hline High & 3.3 & 4.4 & $0.69(0.62-0.76)$ & $0.77(0.69-0.87)$ & 8.7 & 10.1 & $0.86(0.79-0.95)$ & $0.84(0.76-0.93)$ \\
\hline \multicolumn{9}{|l|}{ Lipophilicity } \\
\hline Hydrophile & 3.2 & 4.2 & $0.69(0.62-0.77)$ & $0.78(0.70-0.88)$ & 5.1 & 5.2 & $0.98(0.86-1.11)$ & $0.94(0.83-1.06)$ \\
\hline Intermediate & 0.2 & 0.2 & $0.77(0.50-1.20)$ & $0.88(0.56-1.39)$ & 0.5 & 0.4 & $1.15(0.77-1.73)$ & $1.04(0.69-1.58)$ \\
\hline Lipophile & 1.1 & 1.4 & $0.72(0.60-0.85)$ & $0.81(0.68-0.98)$ & 6.9 & 8.0 & $0.85(0.77-0.95)$ & $0.83(0.74-0.92)$ \\
\hline \multicolumn{9}{|l|}{ First prescription } \\
\hline Yes & 0.2 & 0.2 & $0.93(0.58-1.48)$ & $1.18(0.69-1.99)$ & 0.4 & 0.6 & $0.63(0.42-0.95)$ & $0.62(0.41-0.94)$ \\
\hline \multicolumn{9}{|c|}{ Last prescribed daily dose (DDD) ${ }^{\mathrm{b}}$} \\
\hline$<0.67$ & 0.9 & 1.2 & $0.72(0.59-0.87)$ & $0.81(0.65-1.00)$ & 8.7 & 9.8 & $0.89(0.81-0.98)$ & $0.87(0.79-0.96)$ \\
\hline $0.67-1.33$ & 2.0 & 2.6 & $0.73(0.64-0.83)$ & $0.85(0.74-0.99)$ & 3.2 & 3.4 & $0.95(0.82-1.11)$ & $0.90(0.77-1.06)$ \\
\hline$>1.33$ & 1.4 & 2.0 & $0.64(0.55-0.75)$ & $0.81(0.69-0.97)$ & 0.4 & 0.4 & $0.95(0.61-1.49)$ & $0.85(0.54-1.35)$ \\
\hline
\end{tabular}

a Adjusted for use of other antihypertensive drugs and general risk factors for falls and fractures (see Materials and Methods)

${ }^{\mathrm{b}}$ One DDD is equivalent to $150 \mathrm{mg}$ metoprolol

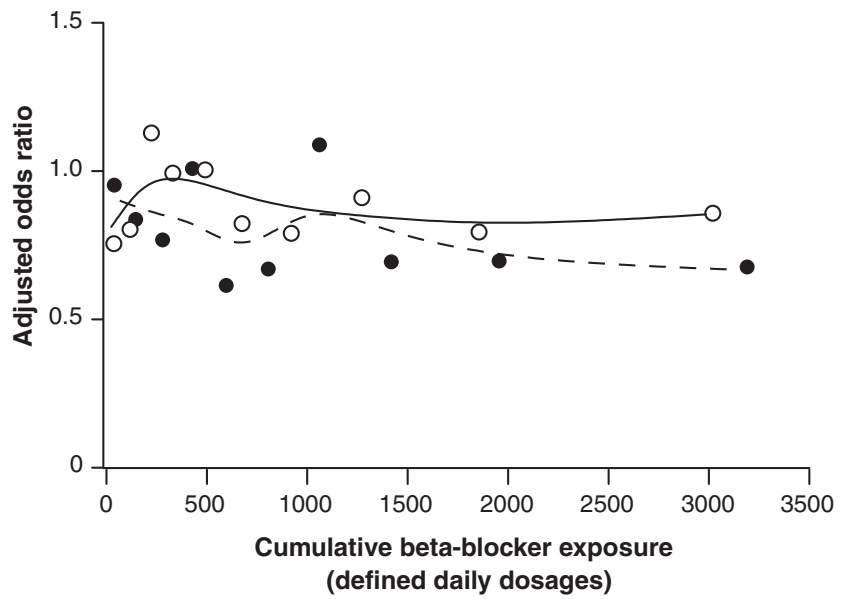

Fig. 1. Spline visualization of cumulative dose among current B-blocker users and risk of hip/femur fractures (GPRD, dashed line, solid circles; PHARMO RLS, solid line, open circles). Cumulative dose is expressed in DDDs (1,000 DDDs are equivalent to $150 \mathrm{~g}$ of metoprolol). Odds ratios were adjusted for the same confounders as in Table 2.

current use of $\beta$-blockers and use of other antihypertensive drugs was statistically significant $(P<0.05)$. Furthermore, no effect of cumulative dose was found in either current users of $\beta$-blocker only or in current $\beta$-blocker users with a history of using other antihypertensive drugs (Fig. 2). Further stratification according to high or low average daily dose during the study period indicated no effect of the intensity of $\beta$-blocker use on the risk estimates.

\section{Discussion}

In both the GPRD and PHARMO RLS data sets, current use of $\beta$-blockers was associated with a decreased risk of hip/femur fractures. However, there was no reduced risk of hip/femur fractures among patients who did not have a history of using other antihypertensive drugs: a protective effect of $\beta$-blockers was only observed for patients with current or prior use of other antihypertensive agents. Even within this group of patients, no dose-response relationship with $\beta$-blocker use was found. The effect was constant with cumulative dose and the OR was below 1.0 even among patients who had just started treatment with $\beta$-blockers. As the mechanism by which $\beta$-blockers could influence BMD is likely to need some time to exert a clinically relevant effect, this finding suggests that the association between $\beta$-blockers and fracture risk is not causal.

Based on in vivo and in vitro studies and the discovery that the central nervous system is involved in the regulation of bone, $\beta$-blockers have been implicated in a preventive role in patients with osteoporosis. Central effects of leptin have been found to be mediated by the sympathetic nervous system, acting via $\beta$ receptors on osteoblasts [3]. $\beta$ agonists stimulate boneresorption activity in osteoclasts [24]. Previous data have shown that systemic application of $\beta$ agonists had a negative effect on bone mass in mice [25], whereas $\beta$ antagonists stimulated bone formation in rats [6]. 
Table 3. Current use of $\beta$-blockers and risk of hip/femur fractures in patient subgroups

\begin{tabular}{|c|c|c|c|c|c|c|c|c|}
\hline \multirow[b]{2}{*}{$\begin{array}{l}\text { Current use of } \\
\beta \text {-blockers }\end{array}$} & \multicolumn{5}{|c|}{ GPRD } & \multicolumn{3}{|c|}{ PHARMO RLS } \\
\hline & $\begin{array}{l}\text { Cases } \\
(\%)\end{array}$ & $\begin{array}{l}\text { Controls } \\
(\%)\end{array}$ & $\begin{array}{l}\text { Crude OR } \\
(95 \% \mathrm{CI})\end{array}$ & $\begin{array}{l}\text { Adjusted OR } \\
(95 \% \mathrm{CI})^{\mathrm{a}}\end{array}$ & $\begin{array}{l}\text { Cases } \\
(\%)\end{array}$ & $\begin{array}{l}\text { Controls } \\
(\%)\end{array}$ & $\begin{array}{l}\text { Crude OR } \\
(95 \% \mathrm{CI})\end{array}$ & $\begin{array}{l}\text { Adjusted OR } \\
(95 \% \mathrm{CI})^{\mathrm{a}}\end{array}$ \\
\hline \multicolumn{9}{|l|}{ Gender } \\
\hline Men & 3.4 & 4.5 & $0.68(0.55-0.84)$ & $0.77(0.60-0.98)$ & 10.1 & 12.0 & $0.83(0.70-0.98)$ & $0.77(0.64-0.93)$ \\
\hline Women & 4.8 & 6.3 & $0.71(0.64-0.78)$ & $0.83(0.74-0.93)$ & 13.3 & 14.4 & $0.93(0.95-1.02)$ & $0.90(0.82-1.00)$ \\
\hline \multicolumn{9}{|l|}{ Age (years) } \\
\hline$<65$ & 2.9 & 3.1 & $0.93(0.68-1.26)$ & $0.91(0.62-0.91)$ & 5.0 & 7.2 & $1.04(0.80-1.35)$ & $0.94(0.70-1.27)$ \\
\hline $65-80$ & 7.0 & 9.1 & $0.71(0.62-0.80)$ & $0.84(0.73-0.98)$ & 14.5 & 16.8 & $0.84(0.58-1.12)$ & $0.80(0.70-0.91)$ \\
\hline $80+$ & 3.5 & 4.6 & $0.65(0.57-0.75)$ & $0.77(0.66-0.91)$ & 12.4 & 13.5 & $0.94(0.84-1.06)$ & $0.94(0.83-1.07)$ \\
\hline \multicolumn{9}{|c|}{ History of any use of other antihypertensive drugs } \\
\hline No & 2.2 & 2.4 & $0.89(0.77-1.04)$ & $0.97(0.82-1.14)$ & 8.3 & 8.1 & $1.02(0.85-1.23)$ & $1.01(0.90-1.14)$ \\
\hline Yes & 9.7 & 14.7 & $0.60(0.53-0.67)$ & $0.73(0.64-0.83)$ & 20.9 & 26.9 & $0.73(0.65-0.83)$ & $0.76(0.67-0.86)$ \\
\hline
\end{tabular}

a Adjusted for use of other antihypertensive drugs and general risk factors for falls and fractures (see Materials and Methods) Percentages represent the proportion of current beta-blocker within each subcategory (e.g. male gender)
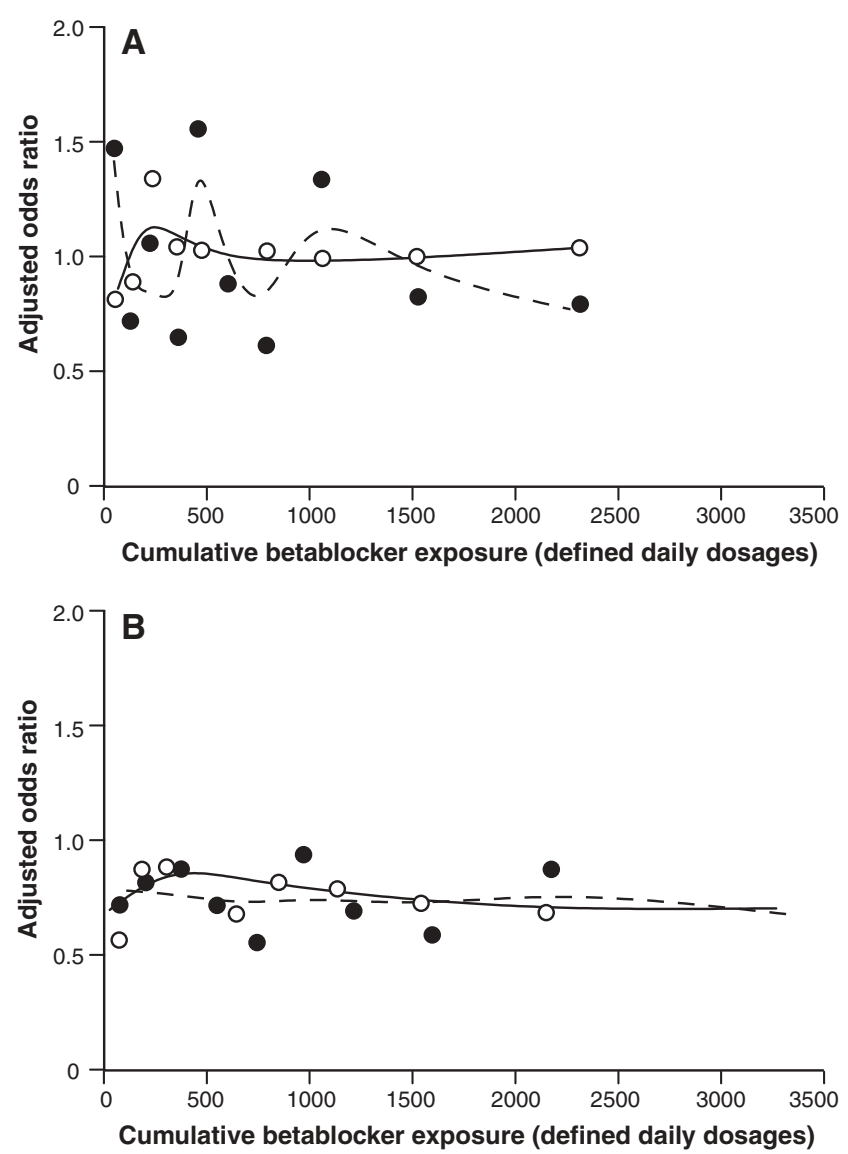

Fig. 2. Spline visualization of cumulative dose among current $\beta$-blocker users, stratified according to patients not having (A) or having a history of other antihypertensive drugs (B) (GPRD, dashed line, solid circles; PHARMO RLS, solid line, open circles). Cumulative dose is expressed in DDDs $(1,000$ DDDs are equivalent to $150 \mathrm{~g}$ of metoprolol). Odds ratios were adjusted for the same confounders as in Table 2, except for the use of antihypertensive drugs.

Several epidemiological studies have reported discrepant results on the association between use of $\beta$-blockers and risk of fracture [7-12], including a study that also used data from the GPRD [8]. The reason for the discrepancy is unclear. Emerging data from randomized controlled trials also support a lack of effect of $\beta$-blockers on the risk of fracture. Recently, a clinical trial among 41 normal postmenopausal women found no evidence that propranolol stimulates bone formation, as measured by bone turnover markers [26]. Furthermore, pooled data from nine clinical trials investigating the nonselective $\beta$-blocker carvedilol in the management of congestive heart failure did not provide evidence in support of an effect of $\beta$-blockers on fracture risk reduction [10]. The data from this meta-analysis are consistent with the results of our study as no effect on fracture was observed in patients treated with $\beta$-blockers without history of other antihypertensive drug use.

Therapeutic uses of $\beta$-blockers include the treatment of hypertension as well as heart failure and secondary prevention post-myocardial infarction, -cardiac dysrhythmia, and -angina pectoris. Cardiovascular disease, heart failure, and hypertension have all been linked with decreased BMD [27-30]. Because thiazides, calcium channel blockers, and inhibitors of the renin-angiotensin system have also been associated with beneficial effects on bone [31], we stratified in our study on history of use of other antihypertensive drugs to separate the effect of current use of $\beta$-blockers from that of other antihypertensive agents. This method of stratification was not applied in earlier epidemiological studies on $\beta$-blockers and fractures.

The strength of our study is that it was populationbased. Furthermore, we found the same results in both the UK and Dutch data sets. The prevalence of $\beta$-blocker use was nearly three times as high in the PHARMO RLS compared to the GPRD. In 2002, 5.1 million prescriptions for $\beta$-blockers were issued in The Netherlands (population 16 million) [32] compared to 22.4 million prescriptions in the United Kingdom in the 
same year (population 59 million) [33]. Taking into account that prescriptions in the United Kingdom are usually for 30 days and those in The Netherlands for 90 days, we can conclude that the observed difference in exposure prevalence is in line with prescribing data volumes in both countries.

Observational studies like ours have potential for bias and confounding and can fuel debates on study interpretation and credibility [34-36]. Various drugs with effects on the central nervous system are known to increase the risk of falls and thereby fracture risk. Also, there are likely to be complex interactions between vascular disease and fracture risk, operating through falls risk, BMD, or common genetic or lifestyle factors. In this study, we had no information on BMD and we cannot exclude the possibility that cases and controls were different with respect to BMD. However, given that initiation of antihypertensive treatment in daily clinical practice will usually be independent of patient BMD, major confounding seems unlikely. Variables included in the final regression models were slightly different between the two data sets due to the nature of the data collections. However, multivariate adjustment had only modest effects on the OR of the exposure of interest. Information on smoking and BMI was not available in the PHARMO RLS database, but adjustment for these factors in the GPRD had no influence on risk estimates (smoking was not retained in the model). Data on BMI were missing for $58 \%$ of the GPRD study population, so we cannot exclude the concern that adjustment was suboptimal. We had no data on physical activity, diet, or socioeconomic status as such information is not available in the databases used in our studies [37]. Furthermore, we cannot exclude the possibility that residual confounding can explain part of our results.

An alternative explanation for our findings could be that the protective effect of $\beta$-blockers on fractures is an artifact caused by selective underuse in patients with an unmeasured comorbidity, a problem that has been described by Glynn et al. in a study on cardiovascular drug use and mortality [38]. In their study, among elderly subjects in the United States, they found that users of drugs from seven commonly prescribed therapeutic classes, including $\beta$-blockers, thiazide diuretics, and angiotensin-converting enzyme inhibitors, had reduced rates of death compared to nonusers, which was more likely to be explained by selective prescribing and nonadherence.

A potential limitation is that we confined our study to hip/femur fractures and did not evaluate other type of fractures. It is possible that potential beneficial effects of $\beta$-blockers are present only at sites other than the hip/ femur, but there is no evidence to support this.

In conclusion, the reduction in hip/femur fracture risk was not related to cumulative dose of $\beta$-blockers and was only present in patients using $\beta$-blockers with a history of using other antihypertensive drugs as well. This suggests that the effect of $\beta$-blockers on hip/femur fracture is not causal.

\section{References}

1. Ducy P, Amling M, Takeda S, et al. (2000) Leptin inhibits bone formation through a hypothalamic relay: a central control of bone mass. Cell 100:197-207

2. Fu L, Patel MS, Bradley A, Wagner EF, Karsenty G (2005) The molecular clock mediates leptin-regulated bone formation. Cell 122:803-815

3. Elefteriou F, Ahn JD, Takeda S, et al. (2005) Leptin regulation of bone resorption by the sympathetic nervous system and CART. Nature 434:514-520

4. Takeda S, Elefteriou F, Levasseur R, et al. (2002) Leptin regulates bone formation via the sympathetic nervous system. Cell 111:305-317

5. Elmquist JK, Strewler GJ (2005) Physiology: do neural signals remodel bone? Nature 434:447-448

6. Minkowitz B, Boskey AL, Lane JM, Pearlman HS, Vigorita VJ (1991) Effects of propranolol on bone metabolism in the rat. J Orthop Res 9:869-875

7. Pasco JA, Henry MJ, Sanders KM, Kotowicz MA, Seeman E, Nicholson GC (2004) Beta-adrenergic blockers reduce the risk of fracture partly by increasing bone mineral density: Geelong Osteoporosis Study. J Bone Miner Res 19:19-24

8. Schlienger RG, Kraenzlin ME, Jick SS, Meier CR (2004) Use of beta-blockers and risk of fractures. JAMA 292:1326-1332

9. Rejnmark L, Vestergaard P, Mosekilde L (2006) Treatment with beta-blockers, ACE inhibitors, and calciumchannel blockers is associated with a reduced fracture risk: a nationwide case-control study. J Hypertens 24:581-589

10. Reid IR, Gamble GD, Grey AB, et al. (2005) $\beta$-Blocker use, BMD, and fractures in the study of osteoporotic fractures. J Bone Miner Res 20:613-618

11. Levasseur R, Dargent-Molina P, Sabatier JP, Marcelli C, Breart G (2005) Beta-blocker use, bone mineral density, and fracture risk in older women: results from the Epidemiologie de l'Osteoporose prospective study. J Am Geriatr Soc 53:550-552

12. Rejnmark L, Vestergaard P, Kassem M, et al. (2004) Fracture risk in perimenopausal women treated with betablockers. Calcif Tissue Int 75:365-372

13. Turker S, Karatosun V, Gunal I (2006) Beta-blockers increase bone mineral density. Clin Orthop Relat Res 443:73-74

14. Pasco JA, Henry MJ, Nicholson GC, Schneider HG, Kotowicz MA (2005) Beta-blockers reduce bone resorption marker in early postmenopausal women. Ann Hum Biol 32:738-745

15. Cummings SR, Melton LJ (2002) Epidemiology and outcomes of osteoporotic fractures. Lancet 359:1761-1767

16. Walley T, Mantgani A (1997) The UK General Practice Research Database. Lancet 350:1097-1099

17. Van Staa TP, Abenhaim L (1994) The quality of information recorded on a UK database of primary care records: a study of hospitalization due to hypoglycemia and other conditions. Pharmacoepidemiol Drug Saf 3:32-34

18. Van Staa TP, Abenhaim L, Cooper C, Zhang B, Leufkens HGM (2000) The use of a large pharmacoepidemiologic database to study exposure to oral corticosteroids and risk of fractures: validation of study population and results. Pharmacoepidemiol Drug Saf 9:359-366

19. Herings RMC (1993) PHARMO A record linkage system for postmarketing surveillance of prescription drugs in The Netherlands. Utrecht University, Utrecht 
20. Van Staa TP, Wegman S, de Vries F, Leufkens B, Cooper C (2001) Use of statins and risk of fractures. JAMA 285:1850-1855

21. De Vries F, van Staa TP, Bracke MS, Cooper C, Leufkens HG, Lammers JW (2005) Severity of obstructive airway disease and risk of osteoporotic fracture. Eur Respir $\mathbf{J}$ 25:879-884

22. World Health Organization (2002) ATC Index with DDDs. Oslo: WHO Collaborating Centre for Drug Statistics Methodology

23. Greenland S (1995) Dose-response and trend analysis in epidemiology: alternatives to categorical analysis. Epidemiology 6:356-365

24. Arai M, Nagasawa T, Koshihara Y, Yamamoto S, Togari A (2003) Effects of beta-adrenergic agonists on bone-resorbing activity in human osteoclast-like cells. Biochim Biophys Acta 1640:137-142

25. Bonnet N, Benhamou CL, Brunet-Imbault B, et al. (2005) Severe bone alterations under $\beta_{2}$ agonist treatments: bone mass, microarchitecture and strength analyses in female rats. Bone 37:622-633

26. Reid IR, Lucas J, Wattie D, et al. (2005) Effects of a betablocker on bone turnover in normal postmenopausal women: a randomized controlled trial. J Clin Endocrinol Metab 90:5212-5216

27. Huopio J, Honkanen R, Jurvelin J, Saarikoski S, Alhava E, Kroger H (2005) Role of chronic health disorders in perimenopausal fractures. Osteoporos Int 16:14041411

28. Afghani A, Johnson CA (2006) Resting blood pressure and bone mineral content are inversely related in overweight and obese Hispanic women. Am J Hypertens 19:286-292
29. Cappuccio FP, Meilahn E, Zmuda JM, Cauley JA (1999) High blood pressure and bone-mineral loss in elderly white women: a prospective study. Study of Osteoporotic Fractures Research Group. Lancet 354:971-975

30. Gotoh M, Mizuno K, Ono Y, Takahashi M (2005) High blood pressure, bone-mineral loss and insulin resistance in women. Hypertens Res 28:565-570

31. Perez-Sactrillon JL, Justo I, Sanz-Cantalapiedra A, Pueyo C, Hernadez G, Duenas A (2005) Effect of the antihypertensive treatment on the bone mineral density and osteoporotic fracture. Curr Hypertens Rev 1:61-66

32. GIP/College voor zorgverzekeringen (2005) http:// www.gipdatabank.nl/index.asp?scherm $=$ lijstTabelsoorten\&infoType $=\mathrm{g}$ (accessed January 26, 2006)

33. Department of Health (2002) Prescription cost analysis: England, http://www.dh.gov.uk/PublicationsAndStatistics/Statistics/StatisticalWorkAreas/StatisticalHealthCare/StatisticalHealthCareArticle/fs/en?CONTENT_ID = 4000027\&chk = FPQDwZ (accessed October 8, 2006)

34. Von Elm E, Egger M (2004) The scandal of poor epidemiological research. BMJ 329:868-869

35. Juni P, Reichenbach S, Egger M (2005) COX2 inhibitors, traditional NSAIDs, and the heart. BMJ 330:1342-1343

36. Vandenbroucke JP (2004) When are observational studies as credible as randomised trials? Lancet 363:1728-1731

37. Farahmand BY, Persson PG, Michaelsson K, Baron JA, Parker MG, Ljunghall S (2000) Socioeconomic status, marital status and hip fracture risk: a population-based case-control study. Osteoporos Int 11:803-808

38. Glynn RJ, Knight EL, Levin R, Avorn J (2001) Paradoxical relations of drug treatment with mortality in older persons. Epidemiology 12:682-689 